\title{
CRÍTICA LITERARIA Y POLÍTICAS DE GÉNERO
}

\author{
PILAR CUDER DOMÍNGUEZ \\ Universidad de Huelva
}

Evaluando la contribución del feminismo a la crítica literaria en 1991, la estadounidense Susan S. Lanser resumía así los logros de las dos décadas anteriores:

«Las feministas identificaron como patriarcales aquellos valores que se estaban transmitiendo como universales; argumentaron que los grandes clásicos eran de hecho los libros que valoraba una élite cultural compuesta por varones blancos de la clase dirigente; y rechazaron la afirmación de que la literatura transciende a la ideología y por tanto debe estudiarse desde el prisma objetivo de la forma estética. Con las pruebas acumuladas mediante una revisión de la historia de la literatura, las feministas pusieron en tela de juicio los juicios de valor y las condiciones materiales en que los textos se escriben, se publican, se interpretan, se preservan, y se canonizan. Esgrimiendo la consigna de que escribir y leer no son actos neutrales, sino que se producen mediante procesos sociales muy complejos, conscientes e inconscientes, el feminismo insistió en que el significado de un texto no se limita a lo que su autor/a 'pretendió,' o a la interpretación defendida por una tendencia crítica en particular.»1

Aunque de esta cita memorable parezca desprenderse una apología claramente optimista de la labor realizada desde el feminismo, Lanser parte de estos logros para examinar también en qué medida la crítica feminista puede y debe seguir luchando por llegar a ser más crítica, más literaria, y si cabe, más feminista. Lanser es mi referencia ineludible en el presente artículo porque, si bien disto mucho de su agudeza y de su argumentación rigurosa y certera, como ella deseo reflexionar sobre las teorías y las prácticas de la crítica literaria feminista en estas últimas décadas, y en particular sobre los dilemas que nos preocupan en los albores del nuevo milenio. ${ }^{2}$ No sería posible en tan breve espacio describir

1. LANSER, Susan S.: «Feminist Literary Criticism: How Feminist? How Literary? How Critical?», NWSA Journal 3.1 (1991), p. 4., mi traducción.

2. Evidentemente no soy la única ni la mejor preparada para enfrentarse a esta tarea en nuestro país. Véanse, como muestra, tres botones: Beatriz SUÁREZ BRIONES, «Feminismos: qué son y para qué sirven» (2000); Marta SEGARRA y Àngels CARABÍ, eds., Feminismo y crítica literaria (2000); y Teresa GÓMEZ REUS, «Topografías feministas: Perspectivas y reflexiones desde la crítica literaria» (2001). 
todas y cada una de las aportaciones de las críticas feministas, ni siquiera restringiéndome al ámbito que me compete más de cerca, el anglosajón, de modo que mi enfoque se referirá muy someramente al modo en que el feminismo ha planteado cuestionamientos de notable importancia en lo referente a la posición de las mujeres en tres facetas que no han de ser vistas como mutuamente excluyentes sino como insoslayablemente complementarias: como autoras, como lectoras y como críticas.

\section{LA CRÍTICA FEMINISTA Y LA AUTORÍA FEMENINA}

El siglo XX pasará sin duda a la historia como el siglo de la recuperación de una tradición literaria propiamente femenina. Todavía a principios del mismo se lamentaba la narradora y ensayista británica Virginia Woolf de la ausencia de precedentes y modelos de su sexo, al tiempo que llamaba la atención sobre los obstáculos materiales a menudo insuperables para las escritoras de épocas precedentes. Hemos de agradecer a dos colegios femeninos de la Universidad de Cambridge, Girton y Newnham, que en 1928 encargaron a Woolf dos conferencias sobre el tema "las mujeres y la novela", algunas de las reflexiones más brillantes sobre la posición de las mujeres en el entramado socio-cultural de la Gran Bretaña de los años 20 (y por extensión, de las mujeres blancas de clase media en las sociedades occidentales).

Medio siglo más tarde, prestigiosas académicas del denominado «segundo feminismo» se atrevieron a recoger el reto de Woolf. Llama la atención cómo la práctica totalidad de los debates actuales se encuentran ya en germen en su ensayo Un cuarto propio (1929). ${ }^{3}$ Así, la recuperación y estudio de la tradición femenina reclamados por Woolf tomaron forma paulatinamente en los trabajos de Ellen Moers, Patricia Meyer Spacks, Elaine Showalter o Nina Baym a lo largo de los 70, y adquirían el marchamo de disciplina gracias a la propia Showalter, quien definía en 1981 la "ginocrítica» como:

«el estudio de las mujeres como escritoras, y sus objetos de estudio son la historia, los estilos, los temas, los géneros y las estructuras de la escritura de mujeres; la psicodinámica de la creatividad femenina; la trayectoria individual o colectiva de las carreras de las mujeres; y la evolución, así como las leyes, de la tradición literaria femenina.» ${ }^{4}$

De modo similar, el análisis woolfiano sobre las condiciones materiales y psíquicas que dificultan la participación femenina en la cultura engendró trabajos de investigación tan valiosos como La loca del desván (1979), que investigaba en detalle la situación de ansiedad psíquica de las escritoras británicas al introducirse en terrenos tradicionalmente masculinos, o Gender and Genius

3. En el presente trabajo, manejo siempre que me es posible las referencias bibliográficas de su traducción al castellano. Cuando no me consta que la obra en cuestión haya sido traducida, mantengo el título original en inglés y traduzco yo misma los fragmentos que preciso.

4. SHOWALTER, Elaine: "La crítica feminista en el desierto", 1981, en Marina FE (ed.): Otramente: lectura y escritura feministas, México D.F., Programa Universitario de Estudios de Género de la Facultad de Filosofía y Letras y Fondo de Cultura Económica, 1999, p. 82. 
(1989), que advertía que «desde los estoicos a los románticos, el léxico relativo a cualidades específicamente femeninas ha sido apropiado para elogiar al varón perfecto» ${ }^{5}$. Susan Gubar, co-autora de La loca del desván, profundizaba en estas cuestiones en su brillante ensayo "La página en blanco' y los problemas de la creatividad femenina.» Ilustrando sus propuestas con el cuento de Isak Dinesen del mismo título, Gubar denuncia:

«Este modelo de la pluma-pene que escribe sobre la página virgen es parte de una larga tradición que identifica al autor como un hombre que es primario y a la mujer como su creación pasiva, como un objeto secundario que carece de autonomía, dotado de significados con frecuencia contradictorios, pero al que se niega intencionalidad. Resulta obvio que esta tradición excluye a la mujer de la creación de cultura, al mismo tiempo que la reifica como un artefacto dentro de la cultura. Por lo tanto, resulta particularmente problemática para aquellas mujeres que desean apropiarse de la pluma al convertirse en escritoras. Especialmente en el siglo XIX, las escritoras, quienes temían que sus ensayos con la pluma fueran presuntuosos, castrantes o incluso monstruosos, emplearon una variedad de estrategias para habérselas con su ansiedad sobre la autoría.. ${ }^{6}$

La equiparación de la reproducción biológica con la creatividad literaria, o en líneas más generales, la relación entre el cuerpo femenino y la obra literaria, ha cristalizado igualmente en otras escuelas de pensamiento feminista. Así, aun cuando habitualmente se viene aceptando sin grandes reservas que las propuestas anglo-americanas y las francesas son irreconciliables, no se da en la práctica un gran salto conceptual entre las afirmaciones de Gubar, que examina cómo escritoras incluso contemporáneas continúan sintiendo el acto de inspiración y creación «como una violación, una reacción tardía a la penetración masculina,... una reacción al desgarramiento ${ }^{7}$ y emplean con frecuencia imágenes relativas a la sangre (virginal, menstrual, o consecuencia de una herida), y las exhortaciones de Hélène Cixous a escribir el texto femenino con la tinta blanca de la leche materna:

"Nos hemos apartado de nuestros cuerpos, que vergonzosamente nos han enseñado a ignorar, a azotarlo con el monstruo llamado pudor; nos han hecho el timo de la estampita: cada cual amará al otro sexo. Yo te daré tu cuerpo y tú me darás el mío. Pero ¿qué hombres dan a las mujeres el cuerpo que ellas les entregan ciegamente? ¿Por qué hay tan pocos textos? Porque aún muy pocas mujeres recuperan su cuerpo. Es necesario que la mujer escriba su cuerpo, que invente la lengua inexpugnable que reviente muros de separación, clases y retóricas, reglas y códigos. ${ }^{8}$

El debate sobre la autoría femenina se encuentra enmarcado por dos procesos que se han desarrollado en las últimas décadas del siglo XX: por un lado,

5. BATTERSBY, Christine: Gender and Genius: Towards a Feminist Aesthetics, London, The Women's Press, 1989, p. 229

6. GUBAR, Susan: "La página en blanco' y los problemas de la creatividad femenina», 1981, en Marina FÉ, (ed.), op.cit., p. 181.

7. GUBAR, op. cit., p. 193.

8. CIXOUS, Hélène: La risa de la medusa. Ensayos sobre la escritura, 1979, Barcelona, Anthropos, Dirección General de la Mujer y Editorial de la Universidad de Puerto Rico, 1995, p. 58. 
la institucionalización del feminismo y de la crítica feminista, y por el otro, el creciente éxito comercial de la literatura escrita por mujeres.

El primero de estos procesos se refiere a la enseñanza de textos femeninos y/o feministas en el contexto universitario. Inicialmente, esto conllevó la elaboración de un anti-canon mediante la deconstrucción del canon masculinista transmitido convencionalmente. Este nuevo canon feminista se desarrolló en el seno de asignaturas y programas dedicados específicamente a estudios de las mujeres, y es el resultado de posiciones políticas separatistas, o si se quiere, de una discriminación positiva. Sin embargo, pasó a ser cuestionado y criticado desde dentro del feminismo, al constatarse que la deconstrucción de los criterios y valores patriarcales no había ido acompañada de la necesaria reflexión sobre otros valores también asumidos tradicionalmente, esto es, los prejuicios raciales, de clase, de orientación sexual, y/o imperialistas.

De hecho, este reproche se hace extensivo a documentos fundacionales del pensamiento feminista como los escritos de Woolf. La escritora afro-americana Alice Walker ofreció una revisión del concepto de la habitación propia en su artículo «In Search of Our Mother's Gardens», al puntualizar que los impedimentos en el acceso a la cultura para las mujeres de color habían obligado a encauzar sus impulsos creativos hacia otros ámbitos más cercanos aunque menos prestigiosos, como el jardín lleno de color que Walker recuerda con admiración.

Este movimiento interno enraizó hacia 1977 entre las críticas feministas afro-americanas, con el influyente trabajo de Barbara Smith "Toward a Black Feminist Criticism», donde se denunciaba la invisibilidad de las escritoras y las lesbianas de color incluso en estudios feministas como los de Spacks y Mores, y aumentó considerablemente a lo largo de la década siguiente. ${ }^{9}$ Así describe Mohanty en su famoso artículo de 1988 «Under Western Eyes» el modo en que la crítica feminista occidental venía tratando la problemática de las mujeres del Tercer Mundo, manejando a este fin un concepto monolítico y ahistórico:

«El primer presupuesto analítico a resaltar está relacionado con la localización estratégica de la categoría "las mujeres» dentro del contexto del análisis. Conceptuar a las mujeres como un grupo ya constituido y coherente, con intereses y deseos idénticos, independientemente de su clase social, etnia o raza, o contradicciones, implica una definición del género o la diferencia sexual o incluso del patriarcado que se extiende universalmente por encima de las culturas. (El contexto analítico en sí puede variar desde las estructuras del parentesco a las organizaciones laborales o a las representaciones mediáticas.) El segundo presupuesto analítico se evidencia al nivel de la metodología, en la forma poco crítica en que se facilitan las "pruebas" de esa validez universal e intercultural. El tercero es un presupuesto más marcadamente político, que subyace en las estrategias analíticas y metodológicas, es decir, el modelo de lucha por el poder que lleva implícito. Quiero hacer notar que, como resultado de esos dos modos (o más bien, marcos) de análisis, se asume una noción

9. Para un análisis de este momento del feminismo véase asimismo mi trabajo «Entre la solidaridad y la diferencia: narradoras norteamericanas de hoy", citado en la bibliografía. 
homogénea de la opresión de las mujeres en grupo, lo que a su vez conduce al patrón de «la mujer media del Tercer Mundo.» Esto contrasta notablemente con la auto-representación (implícita) de las mujeres occidentales como educadas, modernas, que controlan sus propios cuerpos y su sexualidad, y que gozan de la libertad necesaria para tomar sus propias decisiones. $\rangle^{10}$

A raíz de estas argumentaciones, la crítica feminista se ha vuelto en el presente mucho más auto-reflexiva y se ha abierto a otras políticas identitarias, fundamental pero no exclusivamente las de raza. Pero además, la cuestión del canon ha pasado a analizarse más bien desde perspectivas integradoras que segregacionistas, es decir, que existe un acuerdo prácticamente unánime en que la estrategia a seguir consiste más bien en incorporar otras identidades al canon tradicional (asumiendo siempre que todo canon es subjetivo y revisable) que en la construcción paralela de una multiplicidad de anti-cánones.

Simultáneamente, el creciente éxito de ventas, en particular en el campo de la narrativa, ha ido convirtiendo a la literatura de mujeres en un objeto de consumo sometido a las intensas fluctuaciones y manipulaciones del mercado capitalista. De ser fiables los medios de comunicación cuando anuncian en grandes titulares las novedades editoriales referentes a mujeres, deberíamos entender que la total equiparación es un hecho. Con todo, la visibilidad mediática de los últimos tiempos no se corresponde con cifras reales. En su ensayo Literatura y Mujeres, Laura Freixas ha recogido datos referidos al año 1999 en nuestro país al efecto de que las obras publicadas por escritoras representaban el $24 \%$ del total en narrativa; en poesía, el $22 \%$, y en ensayo, el porcentaje descendía significativamente al $15 \%{ }^{11}$.

Por ende, tampoco el criterio cualitativo nos permite ser más optimistas. Desafortunadamente, la crítica literaria que evalúa las novedades editoriales para los suplementos y revistas literarias participa casi por entero del prejuicio de que la literatura "de mujeres» es un género inferior, un producto destinado al consumo de masas (femeninas, huelga decirlo) que no merece sino desprecio en el peor de los casos, y conmiseración paternalista, en el mejor. Cualquier lectora asidua de suplementos como «Babelia» o "El Cultural» habrá constatado la escasez, en cantidad y calidad, de buenas reseñas sobre obras escritas por mujeres.

No puede sorprendernos, así pues, que un número considerable de escritoras (pasadas y presentes) huya como de la peste de la etiqueta «literatura de

10. MOHANTY, Chandra Talpade: "Under Western Eyes: Feminist Scholarship and Colonial Discourses", en Chandra Talpade MOHANTY, Ann RUSSO and Lourdes TORRES, (eds.), Third World Women and the Politics of Feminism, Bloomington, Indiana UP, 1991, pp. 55-56; mi traducción.

Un fragmento de este artículo ha sido vertido al castellano por Marisol MORALES PADRÓN para la revista canaria Nerter: «Bajo la mirada occidental: la crítica feminista y los discursos coloniales", Nerter 2 (2000), pp. 46-9.

11. FREIXAS, Laura: Literatura y mujeres, Barcelona, Destino, 2000, p. 36 . El trabajo de Freixas es riguroso y está muy bien documentado. Véase también el artículo de Lucía Etxebarria: "Con nuestra propia voz: a favor de la literatura de mujeres» recogido en: La Eva futura/La letra futura, Barcelona, Destino, 2000, pp. 105-22. 
mujeres.» La alternativa es abrazarla, como ocurre con antologías y colecciones de indudable calidad y que pretenden dar a las mujeres su espacio propio mediante la segregación del sexo opuesto, pero corremos el riesgo una vez más de vernos encerradas en un gueto del que no podamos salir. ${ }^{12}$

\section{LA CRÍTICA FEMINISTA Y LAS LECTORAS}

Una segunda e igualmente importante línea de pensamiento e investigación desde principios de los 70 fue lo que Showalter denominó, a diferencia de la "ginocrítica», la "lectura feminista», cuya misión estriba en ofrecer "lecturas feministas de textos que examinan las imágenes y estereotipos de la mujer en la literatura, las omisiones y falsos conceptos acerca de la mujer en la crítica, y el lugar asignado a la mujer en los sistemas semióticos» ${ }^{13}$. También aquí Virginia Woolf era un punto de partida significativo, con sus magistrales observaciones sobre la incongruencia entre la historia de las mujeres y la imaginación literaria sobre las mismas:

"Es posible aseverar que las mujeres han ardido como faros en la obra de todos los poetas desde el principio del tiempo. Clitemnestra, Antígona, Cleopatra, Lady Macbeth, Fedra, Cresida, Rosalinda, Desdémona, la Duquesa de Malfi, entre los dramaturgos; luego entre los prosistas: Millamant, Clarisa, Becky Sharp, Ana Karenina, Emma Bovary, Madame de Guermantes -los nombres vienen a la memoria y no para recordar mujeres 'carentes de personalidad y carácter'- En verdad, si la mujer no tuviera más existencia que la revelada por las novelas que los hombres escriben, uno se la imaginaría como un ser de la mayor importancia; muy cambiante; heroica y mezquina, espléndida y sólida; infinitamente hermosa y horrible en extremo; tan grande como un hombre, tal vez mayor.. ${ }^{14}$

Kate Millett adopta una perspectiva similar en su ya famosa tesis doctoral, publicada en 1969 con el título Política sexual ${ }^{15}$. En ella, Millett denunciaba la misoginia implícita en los retratos femeninos de textos literarios habitualmente venerados como "clásicos» modernos, como la controvertida novela de D. H. Lawrence, Lady Chatterley's Lover. Por las mismas fechas, también la escritora Adrienne Rich nos exhortaba a examinar el pasado desde posturas críticas revisionistas en su archi-citado ensayo "When We Dead Awaken: Writing as Re-Vision» ${ }^{16}$.

Poco después se unía a estas dos aportaciones una tercera, de la mano de Judith Fetterley, quien intentaba delimitar las posibles reacciones de una lectora al asomarse al canon estadounidense al uso, tan abundante en imágenes

12. Como ejemplo de antología segregacionista, véase la espléndida compilación poética realizada por Noni Benegas y Jesús Munárriz, citada en la bibliografía.

13. SHOWALTER, Elaine: «La crítica feminista en el desierto», en Marina FÉ, (ed.), op. cit., p. 78.

14. WOOLF, Virginia: Un cuarto propio, 1929, Madrid, Ediciones Júcar, 1991, p. 67.

15. MILLETT, Kate: Política Sexual, Madrid, Cátedra, 1995.

16. RICH, Adrienne: "When We Dead Awaken: Writing as Re-Vision», en On Lies, Secrets, and Silence, Selected Prose 1966-1978, New York, Norton, 1979, pp. 33-49. 
de fuerza y agentividad ${ }^{17}$ viriles como de pasividad y debilidad femeninas. The Resisting Reader ${ }^{18}$ llegaba a la conclusión de que las mujeres se ven obligadas a realizar una lectura "de resistencia», es decir, que deben luchar contra los procesos de identificación que relacionan a lector/a y personaje porque éste representa valores con los que ideológicamente disiente.

La contribución de Fetterley inaugura un ámbito de trabajo sumamente original y que sin embargo continúa siendo arriesgado, puesto que se distancia en parte del texto literario y del autor/a para introducirse en la psique de quien lee desde una perspectiva de género ${ }^{19}$. La crítica del momento tendía a asumir un lector supuestamente neutral y objetivo, término no marcado tras el cual se entreveía claramente al varón como patrón universal. Fetterley, muy al contrario, proponía una lectora «renuente» o «contra-lectora» en relación dialéctica con el texto. ${ }^{20}$

Si tenemos en cuenta que las estadísticas siguen mostrando que las mujeres leen literatura con más asiduidad que los varones (que se decantan en cambio por la prensa diaria ${ }^{21}$, resulta evidente la necesidad de avanzar en el estudio de la recepción femenina de los textos. Los hitos más relevantes en la década de 1980 han sido los trabajos de Patrocinio P. Schweickart y Susan S. Lanser. La primera puso en tela de juicio la dicotomía ginocrítica/lectura feminista defendida por Showalter, pues a su entender no era sino una división arbitraria de lo que en el fondo son dos formas de lectura: la lectura feminista de textos escritos por mujeres y la lectura feminista de textos escritos por varones. Además, construyendo sobre los cimientos de Fetterley, Schweickart argumenta que:

"la literatura androcéntrica estructura la experiencia de la lectura de manera distinta según el género del lector. Para el lector masculino, el texto sirve como lugar de encuentro entre lo personal y lo universal. Se aproxime o no el texto a las particularidades de su propia experiencia, queda invitado a validar la igualdad de lo masculino con lo universal [mientras que la literatura androcéntrica] no permite a la lectora buscar refugio en su diferencia. En lugar de esto, la involucra en un proceso que la usa en contra de sí misma. Busca su complicidad para convertir la diferencia masculina en universalidad y por consiguiente denigrar a la diferencia femenina como una otredad sin reciprocidad. ${ }^{22}$

17. "Agentividad» es un término acuñado en el Seminario de Estudios de la Mujer de la Universidad de Huelva como equivalente al vocablo inglés "agency» y que define en un sentido amplio la capacidad de acción, de ser agente de transformación y cambio en el entorno, en lugar de receptáculo paciente de acciones externas.

18. FETTERLEY, Judith: The Resisting Reader, Bloomington, Indiana UP, 1978.

19. Agradezco a Beatriz Domínguez García sus reflexiones a este respecto, que me ayudaron a percatarme de las deficiencias de la teoría feminista en este campo.

20. Teresa Gómez Reus emplea la traducción «lecturas de resistencia» (op. cit., p. 339), término no sexista que he mencionado igualmente aquí, pero creo que Fetterley tiene en mente en muchas de sus observaciones a una lectora más que una «lectura», y por eso deseo proponer los conceptos de "lectora renuente» o "contra-lectora».

21. Ver FREIXAS, op. cit., pp. 42-7.

22. SCHWEICKART, Patrocinio P.: «Leyéndo(nos) nosotras mismas: hacia una teoría feminista de la lectura», en Marina FÉ, (ed.), op. cit., pp. 126 y 128. 
En consecuencia, la lectura feminista queda definida por Schweickart como la conquista del control de la experiencia de la lectura, una lectura de oposición encaminada a «identificar la naturaleza de las opciones que el texto ofrece $y$, de manera igualmente importante, lo que el texto excluye-es decir, la posibilidad de leer como mujer sin ponerse en la posición del otro, de leer para afirmar la condición de ser mujer como otro paradigma, igualmente válido de la experiencia humana $»^{23}$. Si esta condición se cumple, el texto vendría a convertirse en un punto de encuentro para un diálogo entre la subjetividad de la autora y la subjetividad de la lectora.

Por su parte, Susan S. Lanser sugería en otro artículo ya clásico, "Toward a Feminist Narratology ${ }^{24}$, que podría darse una fructífera convivencia entre los métodos estructuralistas de la narratología y la práctica política del feminismo. Ésta era una propuesta muy controvertida y levantó polémica en las páginas de la prestigiosa revista estadounidense Style a finales de los $80^{25}$. Para Lanser, la narratología no había tenido en cuenta la perspectiva de género ni en la formulación de preguntas e hipótesis de trabajo, ni en los textos mismos sobre los que se basaban, pues se tomaba como "textos universales» lo que eran verdaderamente "textos masculinos", y como ejemplos de ello citaba la definición (fundamentada en Proust) del discurso narrativo de Génette, la morfología de Propp sobre los cuentos tradicionales, los estudios de Iser sobre novelistas varones desde Bunyan a Beckett, o los de Barthes sobre Balzac. Según Lanser, la incorporación del estudio de textos de autoría femenina puede hacer que las teorías narratológicas varíen sustancialmente, en particular en lo concerniente a argumento y relato, más que a elementos de orden más abstracto como el tiempo narrativo ${ }^{26}$.

Los estudios feministas posteriores han buscado profundizar en las características de la mujer lectora, a veces desde planteamientos psicoanalíticos (Mary Jacobus, por ejemplo), otras desde prácticas hermenéuticas tomadas de disciplinas entroncadas con el estructuralismo, como la ya mencionada narratología y la estilística. Aún así, la formulación suele dirigirse hacia los contenidos (es decir, hacia qué textos se lee), más que a la construcción de un modelo teórico de lectura desde la perspectiva de género (es decir, cómo leen las mujeres), si bien tampoco podemos entender que sea esa la meta última, ni siquiera la más deseable, ya que se corre el riesgo de caer en un esencialismo inmovilista. Así, por ejemplo, en su monografía Feminist Stylistics ${ }^{27}$, la británica Sara Mills explica que en la actualidad el análisis feminista se dirige hacia el modo en que los

23. Ibíd., p. 141.

24. LANSER, Susan S.: «Toward a Feminist Narratology», Style 20.3 (1986), pp. 341-63.

25. Al artículo de Lanser, publicado en 1986, dio la réplica la narratóloga Nilli Diengott en 1987, y de nuevo Lanser rebatió las acusaciones de falta de rigor científico el año siguiente, siempre en la misma revista, todo lo cual da cuenta de que se trataba de un encendido y necesario debate sobre los métodos y criterios de esa disciplina.

26. Op. cit., pp. 343-44.

27. MILLS, Sara: Feminist Stylistics, London, Routledge, 1995. 
textos «interpelan» (concepto tomado de Althusser) a las lectoras. Esto es válido para el canon literario tanto como para textos extra-literarios, procedentes de la prensa, la música, o la publicidad. Mills comenta que a menudo un texto va dirigido a un público de un sexo concreto, pero también de una determinada clase social, y a veces de una raza, religión, u orientación sexual particular (caso de numerosos anuncios publicitarios). Mills concluye que:

«aunque el género es un elemento importante en la construcción de la posición del lector/a, no puede ser considerado el único componente ni de ese proceso, ni de su respuesta al texto. Sin embargo, esto no significa que el género no sea un factor significativo del proceso de lectura; más bien, es precisa una visión más compleja de en qué consiste "leer como un hombre o como una mujer», que tenga en cuenta la interacción de otros factores junto con el género. ${ }^{28}$

Relacionada con esta línea de trabajo aparece la necesidad de estudiar las prácticas de las diversas comunidades interpretativas desde una perspectiva de género tanto en diacronía como en sincronía. Un estimulante trabajo de la tristemente desaparecida crítica Lola Luna determinaba, por ejemplo, la emergencia de una comunidad de lectoras en la España del siglo XVI, y trazaba su perfil desde tres ángulos: las lectoras extratextuales (las mujeres «reales») y las intratextuales, unas veces entendidas como destinatarias (en prólogos y dedicatorias de las obras) y otras como lectoras implícitas ${ }^{29}$.

\section{LA CRÍTICA FEMINISTA Y LAS CRÍTICAS FEMINISTAS}

Como mencionaba más arriba, durante el siglo XX la crítica feminista se ha comprometido firmemente con la búsqueda y reconstrucción de una tradición literaria femenina. Esta labor, que podríamos denominar de «arqueología literaria feminista", fue apuntada de nuevo por Virginia Woolf, cuando descubría para sus oyentes británicas los hitos de Aphra Behn, Jane Austen, y las hermanas Brontë. No obstante, a medida que hemos ido reconstruyendo con grandes esfuerzos el desmembrado cuerpo literario de la mujer, hemos ido formulando asimismo los rasgos específicos que lo identifican.

Por ende, dicha definición conlleva el establecimiento de la diferencia con respecto al corpus literario ya existente, y esto ha conducido a diversos razonamientos sobre dónde puede radicar su esencia, es decir, en qué consiste un texto propiamente "femenino». La pregunta nos remite de nuevo a propuestas sobre la écriture feminine de Cixous, o en general, al equiparamiento biologista (y esencialista) de texto femenino y cuerpo femenino, pues el cuerpo aparece como la sede última de la diferencia de género. La escritura del cuerpo se ha entendido como una fuerza disruptora del texto androcéntrico, que a su vez aflora en forma de disrupciones del lenguaje que varían desde una mayor o menor fragmentación del texto a subversiones de sus relaciones sintácticas y

28. Op. cit., p. 79, mi traducción.

29. LUNA, Lola: "Las lectoras y la historia literaria», en Leyendo como una mujer la imagen de la Mujer, Barcelona, Anthropos e Instituto Andaluz de la Mujer, 1996, pp. 102-28. 
lógicas. La poeta Rachel Blau Du Plessis enuncia así el espacio femenino de la escritura:

«¿Escritora? Convertirse en alguien en quien juega el lenguaje y por medio de quien el lenguaje extrae convención poética, etimología, juegos de palabras terribles, giros vernáculos, bocados feos, jerga profesional, balbuceo incoherente, sílabas infantiles, manifestaciones dialectales, rimas infantiles, vieja música pop, adjetivos rebuscados y adjetivos dudosos, conectivos, información periodística, desinformación, conjunciones, pronombres que juegan con el espacio social evocado ('él' 'ella' 'ello' 'nosotros/as' 'ellos/as'), palabras 'pequeñas' como con, el o como. 'Por' quién, junto a quién y hecho por quién puede proceder u ocurrir, declarando la destrucción de la retórica indiscutida (pero nunca la destrucción de la retórica).

¿Escritora? Una posición para activar elementos del lenguaje para que se unan de tal modo que sus actividades obliguen al lector, a ti (a oír un sonido para conocer un espacio que antes 'nunca' fue)..130

De nuevo, esta vinculación intrínseca entre la política sexual y las estéticas vanguardistas, a menudo postmodernas, es altamente criticable desde el feminismo del Tercer Mundo, puesto que asume un modelo unívoco de relación entre «mujer» $y$ «literatura» que toma como referencia exclusiva el Primer Mundo, y porque implica un cierto desdén por poéticas de orden más tradicional en el contexto occidental pero que cumplen idéntica función de denuncia social en otros ámbitos geográficos.

Otro patrón interpretativo que ha cobrado importancia en círculos críticos en estas décadas es el nexo histórico entre sexo/género y género literario. Se ha constatado que las mujeres han encontrado en la novela un terreno literario más propicio, y al mismo tiempo se han reivindicado otras formas de escritura, como cartas, memorias, y diarios, cultivadas asiduamente por las mujeres, y que precisamente por ello no se consideraban estrictamente «literarias.» De este modo ha emergido el discurso autobiográfico en sus variadas manifestaciones como el género "femenino" por antonomasia. Comenta a este respecto Arriaga:

«Los textos autobiográficos femeninos aportan a [la] cultura universal un tipo de identidad más adecuada y reconocible por las mujeres reales, y al mismo tiempo, supone un modelo que contrasta con la idealización de la mujer, que domina en otros géneros de discurso. Al considerar también los textos escritos por mujeres, el valor cognoscitivo de lo autobiográfico, que desde siempre ha incidido sobre cómo imaginamos nuestra realidad y las realidades de otros tiempos históricos que no nos son contemporáneos, propone nuevos modelos de identidades y de identificaciones femeninas, terminando de esta forma con el monopolio del modelo o modelos que la cultura patriarcal ha impuesto e impone.. ${ }^{31}$

30. DU PLESSIS, Rachel Blau: «Otramente», 1985, trad. Natttie Golubov, en Marina FÉ, (ed.): Otramente: lectura y escritura feministas, México D.F., Programa Universitario de Estudios de Género de la Facultad de Filosofía y Letras y Fondo de Cultura Económica, 1999, p. 246.

31. ARRIAGA FLÓREZ, Mercedes: Mi amor, mi juez. Alteridad autobiográfica femenina, Barcelona, Anthropos, 2001, p. 23. 
En consecuencia, la crítica literaria feminista ha venido a reclamar una revisión de la historia y la teoría de los géneros, reivindicando espacios tradicionalmente calificados como extra-literarios por su estrecha relación con la esfera doméstica o privada, es decir, "femenina.» Con todo, es preciso huir una vez más de afirmaciones absolutas de carácter esencialista, pues si bien estas formas literarias más intimistas eran las únicas accesibles a las mujeres en buena parte de nuestra historia, y por tanto han de recibir la atención que se merecen, hoy en día las mujeres están en disposición de cultivar un amplio número de géneros literarios (aun cuando algunos sean más receptivos que otros, dependiendo de factores socio-culturales).

La aproximación autobiográfica, por su vinculación con la representación de la identidad de género, ha tenido también un impacto digno de reseñar sobre la práctica crítica. De aquí han surgido trabajos en los que la académica medita sobre su propio papel en la producción y transmisión del conocimiento, al tiempo que explora su relación con la autora o el texto literario a estudio. Esta fórmula, que se desarrolló en los años 80, entronca asimismo con las propuestas sobre modos de lectura feminista que hemos descrito más arriba. El ejemplo más citado es el artículo de Jane Tompkins, "Me and My Shadow», en el que se presentaba una personalidad dividida entre la función supuestamente objetiva exigida en los círculos académicos y el posicionamiento político de la mujer feminista:

«Hay dos voces en mi interior, dando respuesta al ensayo de Ellen. La una es la voz de una crítica que desea corregir un error en las premisas epistemológicas del mismo. La otra es la voz de una persona que quiere escribir sobre sus sentimientos (hace tiempo que quería hacerlo pero me daba vergüenza). Esta persona cree que es un error criticar el ensayo filosóficamente, y que además da igual, porque el tipo de escrito que esta académica tiene en mente sólo sirve para aislar el discurso académico aún más de los temas que importan al feminismo. Que hacen que ella importe. La crítica, mientras tanto, piensa que esos sentimientos, y las actitudes en que se fundamentan, son sentimentaloides, auto-indulgentes, y poco profesionales.

Estos dos seres existen por separado pero no independientemente. La una escribe para las revistas académicas, la otra en un diario, de madrugada. ...Tal dicotomía es a la vez falsa y auténtica. Quiero decir que en realidad no hay división. Es la misma persona la que siente y la que debate sobre epistemología. El problema es que no podemos hablar de nuestra vida privada mientras desarrollamos nuestra profesión. Tenemos que hacer ver que la epistemología, o el tema sobre el que estamos escribiendo, no tiene nada que ver con nuestra vida, que es más extraordinario, más importante, porque (en teoría) transciende lo meramente personal. Bien, pues estoy harta de los atavismos que mantienen las discusiones sobre epistemología, o sobre James Joyce, segregadas de las reflexiones sobre lo que está ocurriendo en la calle o en mi corazón. La dicotomía público-privado, es decir, la jerarquía público-privado, es uno de los fundamentos de la opresión de las mujeres. Así que a la mierda con ella. El motivo por el que me avergüenzan mis propios intentos de hablar de lo personal en un contexto profesional es porque se me ha condicionado para ello. Y nada más.» ${ }^{32}$

32. TOMPKINS, Jane: "Me and My Shadow», en Linda KAUFFMAN (ed): Gender and Theory: Dialogues on Feminist Criticism, Oxford, Blackwell, 1989, pp. 122-3; mi traducción. 
Esta línea ha sido denominada «crítica personal» por Nancy K. Miller, quien la define como «una práctica explícitamente autobiográfica inserta en un trabajo crítico ${ }^{33}$ que surgió como reacción a la despersonalización de la crítica feminista a medida que se institucionalizaba, y en abierta contradicción con un posicionamiento político que privilegiaba la experiencia subjetiva. Si bien no es hoy en día una fórmula muy extendida, representa un esfuerzo honesto por desentrañar el papel que ocupamos dentro de macro-instituciones de carácter inherentemente político pero que escapan a nuestro control.

\section{CONCLUSIONES: SOBRE CRÍTICAS Y POLÍTICAS}

A lo largo de estas páginas he procurado guiar a mis lectoras a través de un entramado muy complejo de aproximaciones al fenómeno literario desde una perspectiva de género. Inevitablemente, mi visión personal ha determinado el conjunto, seleccionando autoras y textos, matizando planteamientos con los que difiero, alabando aquellos que me parecen valiosos. Sin embargo, no es mi propósito utilizar la autoridad que me confiere hablar desde una revista académica para apoyar una u otra práctica. Al fin y al cabo, la diversidad de propuestas es síntoma de la salud y vitalidad de la crítica feminista. Y más aún, encuentro que todas tienen un valor elevado en tanto en cuanto, cualesquiera que sean sus defectos, parten de una voluntad intrínseca de transformación social.

Virginia Woolf quiso entrar en la biblioteca de la Universidad de Cambridge y se le negó el acceso porque era mujer, y entonces sintió el deseo de prenderle fuego. Hoy estamos dentro de las universidades, y nuestros libros comienzan a poblar los anaqueles de las bibliotecas. Pero la ciencia, el pensamiento «científico", continúa siendo androcéntrico. Hace pocos días conversaba con unas colegas de otras universidades sobre una reciente publicación sobre lenguaje no sexista. Yo argumentaba que encontraba sus propuestas bastante conservadoras, mientras que ellas respondían que eran científicas. Ese es el quid de la cuestión: si somos "científicas» al uso, poco cambio podremos conseguir; si por el contrario, presentamos propuestas más radicales, no se nos considera científicas sino mujeres histéricas, del mismo modo en que todavía una escritora no puede ser una magnífica escritora y una escritora "femenina.»

Este es, a la vez, el reto del nuevo milenio y la gran aportación de los feminismos en el siglo XX. Reflexionar día a día sobre la teoría y la práctica de la ciencia desde una perspectiva de género, sea cual sea la disciplina y la institución desde las que lo hagamos, y con las herramientas que tengamos a nuestra disposición.

33. MILLER, Nancy K.: Getting Personal: Feminist Occasions and Other Autobiographical Acts, London, Routledge, 1991, p. 1. 


\section{BIBLIOGRAFÍA}

ARRIAGA FLÓREZ, Mercedes: Mi amor, mi juez. Alteridad autobiográfica femenina, Barcelona, Anthropos, 2001.

BATTERSBY, Christine: Gender and Genius: Towards a Feminist Aesthetics, London, The Women's Press, 1989.

BENEGAS, Noni, y Jesús MUNÁRRIZ, (eds): Ellas tienen la palabra (Dos décadas de poesía española), Madrid, Hiperión, 1997.

CIXOUS, Hélène: La risa de la medusa. Ensayos sobre la escritura, 1979, trad. Myriam DíazDiocaretz, Barcelona, Anthropos, Dirección General de la Mujer y Editorial de la Universidad de Puerto Rico, 1995.

CUDER DOMÍNGUEZ, Pilar: «Entre la solidaridad y la diferencia: narradoras norteamericanas de hoy», en Beatriz Suárez Briones, $M^{a}$ Belén Martín Lucas, y M Mesús Fariñas, (eds.): Escribir en femenino: poéticas y políticas, Barcelona, Icaria, 2000, pp. 123-40.

DU PLESSIS, Rachel Blau: "Otramente», 1985, trad. Natttie Golubov, en Marina Fé (ed.): Otramente: lectura y escritura feministas, México D.F., Programa Universitario de Estudios de Género de la Facultad de Filosofía y Letras y Fondo de Cultura Económica, 1999, pp. 243-64.

ETXEBARRIA, Lucía: La Eva futura/La letra futura, Barcelona, Destino, 2000.

FETTERLEY, Judith: The Resisting Reader, Bloomington, Indiana UP, 1978.

FREIXAS; Laura: Literatura y mujeres, Barcelona, Destino, 2000.

GÓMEZ REUS, Teresa: «Topografías feministas: Perspectivas y reflexiones desde la crítica literaria», en Ricardo Miguel Alfonso, (ed.): Historia de la teoría y la crítica literarias en Estados Unidos, Madrid, Verbum, 2001, pp. 328-72.

GUBAR, Susan: "La página en blanco' y los problemas de la creatividad femenina", 1981, trad. Julia Constantino, en Marina Fé (ed.): Otramente: lectura y escritura feministas, México D.F., Programa Universitario de Estudios de Género de la Facultad de Filosofía y Letras y Fondo de Cultura Económica, 1999, pp. 175-203.

LANSER, Susan S.: «Toward a Feminist Narratology», Style 20.3 (1986), pp. 341-63.

LANSER, Susan S.: «Feminist Literary Criticism: How Feminist? How Literary? How Critical?», NWSA Journal 3.1 (1991), pp. 3-19.

LUNA, Lola: "Las lectoras y la historia literaria», en: Leyendo como una mujer la imagen de la Mujer, Barcelona, Anthropos e Instituto Andaluz de la Mujer, 1996, pp. 102-28.

MILLER, Nancy K.: Getting Personal: Feminist Occasions and Other Autobiographical Acts, London, Routledge, 1991.

MILLETT, Kate: Política Sexual, Madrid, Cátedra, 1995.

MILLS, Sara: Feminist Stylistics, London, Routledge, 1995.

MOHANTY, Chandra Talpade: «Under Western Eyes: Feminist Scholarship and Colonial Discourses», en Chandra Talpade Mohanty, Ann Russo and Lourdes Torres (eds.), Third World Women and the Politics of Feminism, Bloomington, Indiana UP, 1991, pp. 51-80.

MORALES PADRÓN, Marisol, (trad.): «Bajo la mirada occidental: la crítica feminista y los discursos coloniales», Nerter 2 (2000), pp. 46-9.

RICH, Adrienne: "When We Dead Awaken: Writing as Re-Vision», en Adrienne Rich: On Lies, Secrets, and Silence, Selected Prose 1966-1978, New York, Norton, 1979, pp. 33-49.

SCHWEICKART, Patrocinio P.: «Leyéndo(nos) nosotras mismas: hacia una teoría feminista de la lectura», 1989, trad. Claudia Lucotti, en Marina Fé (ed.): Otramente: lectura y escritura feministas, México D.F., Programa Universitario de Estudios de Género de la Facultad de Filosofía y Letras y Fondo de Cultura Económica, 1999, pp. 112-51. 
SEGARRA, Marta, y Àngels CARABÍ (eds): Feminismo y crítica literaria, Barcelona, Icaria, 2000.

SHOWALTER, Elaine: "La crítica feminista en el desierto», 1981, trad. Argentina Rodríguez, en Marina Fé, (ed.): Otramente: lectura y escritura feministas, México D.F., Programa Universitario de Estudios de Género de la Facultad de Filosofía y Letras y Fondo de Cultura Económica, 1999, pp. 75-111.

SMITH, Barbara: "Toward a Black Feminist Criticism», en Elaine Showalter (ed.): The New Feminist Criticism, London, Virago, 1985, pp. 168-85.

SUÁREZ BRIONES, Beatriz: «Feminismos: qué son y para qué sirven», en Iris M. Zavala, (ed.): Feminismos, cuerpos, escrituras, Sta. Cruz de Tenerife, La página ediciones, 2000, pp. 35-48.

TOMPKINS, Jane: "Me and My Shadow», en Linda Kauffman (ed): Gender and Theory: Dialogues on Feminist Criticism, Oxford, Blackwell, 1989, pp.121-39.

WALKER, Alice: In Search of Our Mother's Gardens, New York, Harcourt, Brace, Jovanovich, 1983.

WOOLF, Virginia: Un cuarto propio, 1929, trad. Jorge Luis Borges, Madrid, Ediciones Júcar, 1991. 